\title{
The Sociobiology of Bereavement: A Reply to Littlefield and Rushton
}

\author{
John Archer \\ Lancashire Polytechnic, Preston, Lancashire, United Kingdom
}

\begin{abstract}
This article offers a critique of Littlefield and Rushton's (1986) application of sociobiological principles to bereavement following the death of a child. The following general issues are considered: (a) whether behavior is always adaptive and (b) the distinction between proximate and ultimate explanations. It is argued that grief is a maladaptive by-product of another, adaptive feature and that hypotheses about the severity of grief are best derived from proximate considerations rather than genetic relatedness. The use of a single-item rating scale to measure grief is questioned, and it is noted that interspouse reliabilities reported in the article were low, a problem not solved (as claimed) by aggregation. Criticisms are made of the specific hypotheses, notably in terms of their origins in sociobiological theory. It is argued that functional hypotheses are not alternatives to proximate mechanisms, but enable some proximate mechanisms to be viewed from the perspective of evolutionary biology.
\end{abstract}

Using a sociobiological perspective, Littlefield and Rushton (1986) derived a number of predictions about the severity of grief following the death of a child, mostly on the basis of the degree of relatedness of the bereaved to the deceased. The predictions were then tested using data from a single-item rating scale, answered by the child's parents, about the degree of grief they perceived themselves and various other relatives of the child as having shown. The study raised a number of contentious issues concerning the application of functional explanations, derived from evolutionary theory, to human behavior. It also neglected to answer the central question crucial to any evolutionary functional analysis, namely what (if any) is the adaptive significance of the behavior being considered; in this case, grief.

In addition, Littlefield and Rushton's (1986) study suffered from a number of methodological weaknesses, such as the use of a single-question rating scale to estimate the severity of grief, low interrater reliability (i.e., discrepancies between mothers' and fathers' ratings), and an overreliance on statistical significance without considering the magnitude of the effects.

In the first part of this reply, I consider general issues raised by Littlefield and Rushton's (1986) article; in the second part, how these and other considerations affect their specific hypotheses. The general issues are as follows:

1. The application of sociobiological concepts to humans.

2. The distinction between proximate and ultimate explanations of behavior.

3. The adaptive significance of grief.

I would like to thank the following for their helpful comments on an earlier draft of this article: John Lazarus (University of NewcastleUpon-Tyne); Patrick Bateson (University of Cambridge); Maria Leek and Peter K. Smith (University of Sheffield); Barry McCarthy and Paul Pollard (Lancashire Polytechnic); and Ian Vine (University of Bradford).

Correspondence concerning this article should be addressed to John Archer, School of Psychology, Lancashire Polytechnic, Preston, PR1 2TQ, Lancashire, United Kingdom.
4. The complexity of the grief process.

5. The reliability of the rating scale.

6. Effect size measures as indicators of the magnitude of effects.

\section{General Issues}

\section{The Application of Sociobiological Concepts to Humans}

Most of the major concepts of sociobiology have been derived from the application of the principles of natural selection to the study of animal behavior. This process involves (a) assumptions derived from the principle of natural selection, (b) the construction of theoretical models, and (c) the empirical testing of such models (e.g., Krebs \& Davies, 1986; Lazarus, 1987). Critics of this approach have sought to question the basis of what they termed the adaptationist program: the assumption that every form of animal behavior must be adaptive, that is, contribute to reproductive fitness. For behavior such as food foraging, this is often taken to imply that it must be optimal in a design sense. Three possible objections to these assumptions are discussed in the following paragraphs.

First, Lewontin (1978, 1979) and Gould and Lewontin (1979) have pointed out that optimal solutions are not always possible, owing to structural constraints in evolution or incompatibility with genetic mechanisms. These criticisms have now been accepted by many animal sociobiologists (or behavioral ecologists), so that recognition of constraints on optimal solutions now assumes more prominence in the testing of specific models.

A second possible limitation to the assumption that behavior must be adaptive is the demonstration that some responses can be maladaptive in specific circumstances, as they form by-products of a feature that is adaptive when viewed in a more general context. The stress response is an example: In functional terms, it can be viewed as a maladaptive consequence of prolonged activation of the fight-or-flight response, the physiological components of which mobilize the body's energy reserves in cases of potential danger (Archer, 1979; Lewontin, 1977). 
A third objection to the so-called adaptationist program is that animals may not be adapted to their current environment because it has changed from a previous one, and the animals have not had sufficient time to evolve adaptations to the new conditions. Most sociobiological models test the current survival value of a behavioral characteristic, although its original survival value in the past environment may have been quite different from its current utility (see Gould \& Vrba, 1982).

Providing these limitations are recognized, and the models based on functional assumptions are used in a predictive wayto guide empirical research-functional and evolutionary approaches can contribute a great deal to the understanding of animal behavior (Archer, 1986; Bateson, 1984, 1985; Krebs \& Davies, 1986). In the human case, however, there are even more potential problems in applying the assumption of adaptation. Culture provides a fundamental problem (Smith, 1983), as it can (and often does) enable human beings to behave in ways that are obviously not adaptive in the sense of enhancing reproductive fitness. To what extent the addition of culture interferes with the assumption that behavior is or was adaptive, or is a byproduct of some other adaptive feature, continues to be debated (e.g., Crook, 1980; Kitcher, 1987; Smith, 1983). An additional problem concerns the great difference between current human environments and those operating during evolutionary history. This greatly magnifies one of the problems raised previously: the difficulty of generalizing from inferences based on current utility to the evolutionary environment.

These general problems provide a number of potential pitfalls for any endeavor that seeks to apply adaptive principles to human behavior. Littlefield and Rushton (1986) omitted to consider whether grief itself is adaptive, or whether it is the byproduct of some other adaptive feature, or whether it was once adaptive but no longer is so. However, before discussing the adaptive significance of grief, it is necessary to outline a further general issue that often leads to confusion in the application of sociobiological explanations to human behavior: the distinction between proximate (causal) and ultimate (functional and evolutionary) explanations of behavior.

\section{Proximate and Ultimate Explanations of Behavior}

Evolutionary functional explanations of behavior are concerned with the behavior's consequences for fitness; that is, whether a particular form of behavior results in an animal leaving more offspring that will survive and reproduce themselves; or more precisely, whether the behavior aids the reproductive chances of that individual or those with similar genetic composition (this is known as inclusive fitness; Hamilton, 1964; see also Grafen, 1982). Many forms of behavior directly or indirectly increase inclusive fitness, but the causal mechanisms underlying the control of the behavior may be only indirectly related to its ultimate function. For example, kin recognition is important (in functional terms) for the social behavior of birds and mammals (e.g., for mate selection), but the mechanism through which they come to recognize their kin is in many cases indirect, as a result of association in a common rearing environment (e.g., Bateson, 1980, 1982b; Halpin \& Hoffman, 1987; Sackett \& Frederickson, 1987). Such indirect ways of achieving functional ends generally work well in the animals' usual envi- ronment (i.e., in their environment of evolutionary adaptiveness; Bowlby, 1969), but may become maladaptive in a different environment.

In other cases, animals show more flexibility in their behavioral mechanisms, so that they can respond in ways which are adaptive when the circumstances change. There are many examples of studies showing such adaptive flexibility; for example, in feeding strategies (e.g., Carpenter \& Macmillan, 1976; Gill \& Wolf, 1975), mating systems (e.g., Davies \& Lundberg, 1984; Fricke, 1980), and parental behavior (e.g., Carlisle, 1982; Wells, 1981).

In applying sociobiological principles to human or animal behavior, it is important to distinguish between the consequences for fitness (ultimate explanation) and the way this is achieved in terms of mechanism (proximate explanation). As previously indicated, proximate mechanisms may either be based on very different principles from those involved with functional considerations, or they may show the capacity for adaptive flexibility.

In the following section I consider how these general issues apply to Littlefield and Rushton's (1986) analysis of grief.

\section{The Adaptive Significance of Grief}

Littlefield and Rushton (1986) failed to address three questions concerning the adaptive significance of grief that are crucial to their hypotheses: first, whether grief is of selective advantage at all; second, in what way it is proposed to increase fitness; and third, why severity of grief should differ adaptively between survivors and between certain conditions.

The only answer to the first question found in Littlefield and Rushton's (1986) article was an extraordinary quote from Barash: that in the process of bereavement we are "hearing the wail of frustrated genes" $(1979 ;$ p. 99$)$, a quote that well illustrates the deterministic nature of much early sociobiological writing (cf. Bateson, 1985; Kitcher, 1987).

If one inquires as to whether bereavement has adaptive consequences by examining the empirical evidence, it soon becomes clear that it does not. In fact, the process of grief is associated with physiological stress, loss of appetite, loss of weight, loss of sexual interest, depression, increased alcohol and drug consumption, poorer health, and increased risk of mortality (Bowlby, 1980; Parkes, 1972, 1985, 1986; Parkes \& Weiss, 1983). Viewed in terms of contributions to inclusive fitness, bereavement is, therefore, a maladaptive state. As it is a widespread or near-universal reaction to loss in the human and other species (Bowlby, 1961; Pollock, 1961; Rosenblatt, Walsh, \& Jackson, 1976), the most likely explanation of its evolutionary origin is that it is associated with or a by-product of another feature that is fitness-enhancing, as was indicated for the stress response.

Parkes (1972) viewed bereavement as the cost of commitment, that is, as a by-product of the mechanisms that establish the close personal relationships necessary, in functional terms, for ensuring a parental unit and for child rearing. These mechanisms involve principles such as exposure learning (Bowlby, 1969; Weiss, 1982), which result in the relationship becoming highly resistant to perceived changes in the outside world that affect its stability, leading to emotional and cognitive states such 
as jealousy (e.g., Daly, Wilson, \& Weghorst, 1982; Mathes, Adams, \& Davies, 1985) and separation reactions (Bowlby, 1973).

Bowlby (1973) also viewed the immediate responses to separation from a loved one (preoccupation, searching, anger) as features that in the majority of cases are adaptive, as they help to reunite the individual with the lost person. However, these same responses occur following separation for any reason, including death, where reunification is obviously impossible. Because, Bowlby argued, such cases are only a small minority of the total number of separations experienced, the responses would, when viewed from this wider perspective, be adaptive. However, the mechanisms involved operate irrespective of whether the response is adaptive in that particular instance. This again illustrates the importance of distinguishing between ultimate and proximate explanations.

So far, I have argued that grief is a maladaptive feature associated with a broader, generally adaptive feature, the relationship with the deceased, and possibly with reactions to temporary separation. These points are not considered in Littlefield and Rushton's (1986) article. However, it might be argued that Littlefield and Rushton were not directly concerned with whether bereavement is adaptive, but only with the question of whether differences in grief severity between relatives follow the genetic relatedness with the deceased in an adaptive way. Assuming for the moment that this was what was meant (although it is not stated in the article), it is then necessary to consider the distinction between ultimate and proximate explanations. Although Littlefield and Rushton refer to this distinction in their Discussion section, it did not inform the planning of their investigation, so that most of their hypotheses were derived directly from the degrees of genetic relatedness of the individuals concerned rather than a consideration of relevant proximate mechanisms. In the case of a child's death, the severity of grief reactions may correspond to kinship patterns, as Littlefield and Rushton predicted, but this is likely to result from a parallel between the closeness of genetic relationships and the closeness of the personal relationship. The latter proximate explanation could have been predicted on the basis of attachment theory (seen as both an alternative theory and a different level of explanation in Littlefield and Rushton's Discussion section). Of course, this consideration does not apply to their hypotheses concerning sex and health or certainty of paternity, although as indicated in a later section, other criticisms can be made of these.

\section{The Complexity of the Grief Process}

The problems involved in applying a sociobiological perspective to bereavement are compounded in Littlefield and Rushton's (1986) article by several methodological difficulties, which are discussed in this and the following sections.

In measuring the extent of grief by asking the respondents to estimate their grief intensity during a 3-month period along a 7-point scale, Littlefield and Rushton (1986) contracted what is acknowledged to be a complex process that changes over time and can extend over a period of several years into a single state. As Parkes (1970) remarked, grief is a process, not a state. Its complexity can be illustrated by listing first its various components, second how it changes over time, and third the extent to which it is influenced by a wide variety of contextal factors.
These include the circumstances of the loss, the quality of the relationship, the personality and temperament of the bereaved, and the degree of social support experienced during bereavement.

Parkes (1985) described the process of grief as consisting first of an acute episodic component and second of a chronic background disturbance. The first component is comprised of features such as restlessness, pining for the lost loved one, the urge to search, anxiety, anger, guilt and preoccupation with thoughts of the deceased, identification phenomena, and mitigation or defenses (see also Parkes, 1970, 1972, 1986; Rosenblatt, 1983). The second component consists of depressive symptoms, inhibition of appetite and other activities, and physiological indications of a stress response. Parkes (1970) found that the relation between these various features was complex. For example, although restlessness was related to tension and anger, these were not significantly correlated with preoccupation.

The realization that grief involves complex changes over time can be found in the attempts to apply a stage theory to the grieving process (Bowlby, 1960, 1980). The stage approach was originally based on studies of separation in children. However, longitudinal studies of adult grief (Lund, Caserta, \& Dimond, 1986; Parkes, 1970, 1972, 1986; Schuchter, 1986) suggest that the changes over time are more complex and more variable than a stage theory can encompass (Archer \& Rhodes, 1987; Lund et al., 1986).

The influence of the wide variety of contextual factors on the process of grieving is summarized in Parkes's (1985) review, under four headings: the type of death, the characteristics of the relationship, the characteristics of the survivor, and the social circumstances. Although these are convenient distinctions, they do, of course, influence one another. Parkes and Weiss (1983) have studied three aspects of the first two factors, namely whether the death was anticipated and whether the relationship involved a high degree of dependence and whether it involved conflict. In all three cases, the nature of the grieving process was affected in severity, in duration, or in whether it occurred immediately after the death or was delayed.

In summary, the complexity of the grief process-in particular, the dissociation of particular aspects of grief from one another-should make one skeptical of evidence on the severity of grieving obtained from a single-item rating scale. Indeed, it is unlikely that grief can be meaningfully quantified in such terms.

\section{The Reliability of the Rating Scale Used by Littlefield and Rushton}

Littlefield and Rushton (1986) assessed the correlation between ratings of the respondants' grief given by themselves and their spouses. The result was 0.5 , indicating that $25 \%$ of the variance in one score is accounted for by the other partner's rating. The between-spouse ratings for grief shown by other members of the family ranged from 0.32 to 0.72 , with ratings of the maternal grandmother showing the highest agreement and those of the maternal grandfather the lowest.

Littlefield and Rushton (1986) appeared unconcerned about the low magnitude of these correlations, concluding that "the ratings were both sufficiently reliable and valid to test the pre- 
dictions" (p. 799). Such a conclusion was presumably reached by ignoring the magnitude of the correlation and concentrating on the significance level. However, a significant correlation merely indicates that the two values are unlikely to be unrelated. It would indeed be surprising if the two ratings were unrelated. However, the crucial issue is whether they are related sufficiently highly to produce reliable measures. Judged as a level of interrater or interobserver reliability, 0.5 would be regarded as unacceptably low (Martin \& Bateson, 1986).

In their discussion, Littlefield and Rushton (1986) advocated aggregation over a number of different ratings as a way of overcoming interrater unreliability. Aggregating over a number of independent data points can increase the sample size, and consequently may produce a higher level of significance for an effect in a consistent direction, but it will not turn an effect of low magnitude into a larger one (although it should reduce the error variance).

In testing the specific hypotheses, Littlefield and Rushton (1986) sought to overcome the discrepancies between the spouses' ratings by adding them together (i.e., again aggregating). There are two specific problems with this method. The first is that the two raters' data points concern the same target individual, so that to aggregate them (as opposed to taking their means) effectively increases the total sample size by using repeated measures on the same subjects (the pooling fallacy; Martin \& Bateson, 1986, pp. 28-29). One consequence of this procedure is to invalidate the results of the analysis of variance (ANOVA) presented in their Table 2.

The second problem with aggregating the two ratings is that the procedure was justified on the basis that none of the male ratings were in the opposite direction to the predictions; this argument concentrates on the direction of the effect while ignoring magnitude. It should, however, be noted that in two of eight cases the magnitude of interrater discrepancy was near to an effect size of $d=0.5$, which is similar to many effects of treatments on behavior that have been the subject of psychological investigations (Cohen, 1977; Hyde, 1981).

\section{Effect Size Measures as Indicators of the Magnitude of Effects}

Failure to distinguish between statistical significance and the magnitude of an effect was referred to in the previous section in relation to reliability. It is also apparent in the interpretation of Littlefield and Rushton's (1986) ANOVA results. Hypotheses were assessed according to whether the results were statistically significant in the predicted direction; all the predictions were directional ones. However, if predictions are derived from quantitative arguments (in this case, genetic relatedness), this should enable them to be presented in quantitative terms, that is, to involve predictions of the magnitude of effects to be expected. As the direction of the effects predicted by genetic relatedness often corresponds to the direction of effect that would be expected on the basis of proximate (nonsociobiological) hypotheses, such as closeness of personal relationships, it is indeed crucial for magnitude of effects to be predicted if the two hypotheses are to be distinguished, as Littlefield and Rushton seek to do (although I have argued that such hypotheses are only alternatives if they are both referring to the same level of analysis).
The general importance of considering the magnitude of effects has been recognized in recent years, particularly in relation to the development of meta-analytic techniques (Glass, McGaw, \& Smith, 1981; Rosenthal, 1984) and critiques of overreliance on probability testing in psychology (Oakes, 1986).

\section{Specific Hypotheses}

I now examine Littlefield and Rushton's (1986) specific hypotheses, in terms of their origins in sociobiological theory and how the previously outlined general issues apply to them.

The first hypothesis predicted that mothers will grieve more than fathers. This was based on a very general interpretation of Trivers's (1972) parental investment hypothesis. In fact, more precise predictions should have been derived from this model and refinements of it (e.g., Dawkins \& Carlisle, 1976; Maynard Smith, 1977) to take into account differences among species. In polygynous species such as the elephant seal, one should expect little or no parental investment by the male, and hence (according to Littlefield \& Rushton's, 1986, argument), little or no grief by the male when a pup dies; on the other hand, in a monogamous species, one would expect much more investment by the male, and consequently, similar reactions from the male and female. In the human case, the sexual dimorphism in size suggests that our species is intermediate between the two. On comparative grounds, it has been suggested that an essentially mildly polygynous mating system, subject to the modifying influence of resource availability and cultural rules, operates in humans (e.g., Crook, 1980; Hrdy, 1981; Short, 1980). Consequently, there is variability in the father's contribution to child care and his perception of the opportunity to father additional children (cf. Maynard Smith, 1977). It is therefore difficult to predict any specific hypothesis from sociobiological principles without considering the ecological and cultural conditions that are operating. The results reported by Littlefield and Rushton, that mothers said they grieved more than fathers did, can in proximate terms be predicted from their closer personal relationships with the child, associated with the greater initial biological contact, followed by more interaction with the child.

The second hypothesis concerned the child's health and predicted that grief for a healthy child would be greater than for an unhealthy child. This was derived from the assumption that a child's health is necessarily correlated with future reproductive success, although Littlefield and Rushton (1986) offered no evidence for this assumption. Their finding, although not significant, was in the predicted direction. However, it should be noted that the same prediction could also have been made on the basis of a proximate hypothesis, in terms of anticipation of possible mortality (Parkes, 1986; Parkes \& Weiss, 1983).

The third hypothesis was that grief for sons would be more pronounced than for daughters, and this was found to be the case. Although the $P$ value was only 0.03 , there was a fairly large effect size of $d=0.98$ (calculated from Littlefield \& Rushton's Table 2, according to Hedges \& Becker, 1986), owing to the high variance. Again, a proximate explanation, in terms of the additional value of male children to parents in a male-dominated society, is readily available. In this case, a supposed sociobiological explanation is lacking, as Littlefield and Rushton based their hypothesis on cross-cultural data, admitting that in view 
of the equal sex ratio, it is unlikely that higher fitness results from favoring one sex or the other during rearing.

The fourth hypothesis concerned a predicted interaction between the health and sex of the child, which specified an order effect that was not found: The respondents reported that grief for a healthy male child was more pronounced than for the other three categories, but these did not differ among themselves. In addition, as Lazarus (personal communication) pointed out, the rank ordering of the four child classes cannot be properly predicted from sociobiological principles without knowing how the categories of healthy and unhealthy relate to reproductive success. (However, judging by the definition given by Littlefield \& Rushton, 1986 , p. 800 , the category unhealthy contained a mixture of children who had long-lasting childhood illnesses and children with physical or mental handicaps; if these two categories were particularly common, it could be assumed that unhealthy boys and girls would both have had low expected reproductive success.)

The fifth hypothesis predicted that perceived similarity (assumed to result from genetic similarity) is associated with higher levels of grief. It was tested by asking parents which side of the family the child resembled, and a significant effect was found. It should, however, be noted that this hypothesis was based on phenotypic or perceived similarity rather than a more direct assessment of genetic similarity, and consequently tested a proximate rather than an ultimate (or sociobiological) explanation (although in this case I would accept that the two are likely to be closely related).

The next three hypotheses (Numbers 6-9) were all concerned with factors that affect the expected relative parental investment in the particular child who has been lost. Although it is not explicitly stated, the general view that parents invest more in their offspring according to the offspring's age, the parents' ages, and the number of other offspring is one that can be traced to Fisher's (1930) concept of reproductive value (an age-specific measure of an animal's potential contribution to future generations), and to more recent theoretical papers that emphasize the relation between parental investment and the cost of replacing offspring to their present stage of development (Dawkins \& Carlisle, 1976; Maynard Smith, 1977; Trivers, 1972).

Of these three specific hypotheses, the first is that parents grieve more strongly for older children than for younger ones, because they have invested more time and energy in them. Although no source is cited, this prediction would appear to come from Trivers (1972). It is, however, unsound at a functional level, as parental investment decisions are selected as a function of their consequences for fitness, not as a result of earlier investments (Dawkins \& Carlisle, 1976). This logical flaw is known as the Concorde fallacy in European ethological writings, after the similar argument made in relation to the development of the Concorde airplane (Dawkins, 1976; Dawkins \& Carlisle, 1976). In functional terms, what matters in guiding parental behavior, such as provisioning and guarding the offspring, is the future investment that would be required to replace the offspring to the current stage of development. At the proximate level, some animals use past investment as an approximate guide or rule of thumb (e.g., Carlisle, 1985; Coleman, Gross, \& Sargent, 1986), whereas others base their decisions only on current circumstances (Carlisle, 1982, 1985; Robertson \& Bier- mann, 1979). Which of the two possibilities occurs may depend on how predictable the animals' past (evolutionary) environment has been (Carlisle, 1985). Nevertheless, it is still possible to obtain the same prediction as Littlefield and Rushton (1986), but on the basis that older children have a higher reproductive value (Lazarus, personal communication).

The other two hypotheses affecting expected parental investment relate to the age of the parent and the number of other surviving children. In the animal kingdom one generally expects higher parental investment by older parents (e.g., Andersson, Wiklund, \& Rundgren, 1980; Tallamy, 1984; Williams, 1966); the influence of the total number of offspring on parental investment is more complex and may depend on the type of parental investment involved, whether shared out over all the offspring or concentrated on a proportion of them (Lazarus \& Inglis, 1986). The proximate mechanisms mediating these general rules have evolved to operate in the environment in which the species has evolved. One cannot, therefore, make precise predictions about what will occur in modern humans from functional considerations alone. Such predictions depend on the degree to which current circumstances differ from those operating in the evolutionary environment, and how such differences affect the proximate mechanisms. Among the sample used in Littlefield and Rushton's (1986) study, the number of offspring produced and the probability of any one of them dying would be very much lower than during human evolutionary history (and indeed from what has operated at most other times in human history and what operates in the majority of the third world today).

One should, therefore, not be surprised that all three hypotheses concerning parental investment were unsupported by the initial correlations presented by Littlefield and Rushton (1986). When child's age was controlled, the correlation between intensity of grief and parents' ages was in the opposite direction to that predicted. When parent's age was controlled, the correlation between grief intensity and the child's age was positive and significant; however, both effects were very small ( $r=-0.12$ and $r=0.11$, indicating that they accounted for $1.4 \%$ and $1.2 \%$ of the variance, respectively).

Hypothesis 9 was based on genetic relatedness, and predicted that of the four grandparents, maternal grandparents would grieve the most and paternal grandfathers the least. Examination of Littlefield and Rushton's (1986) data in their Table 3 shows that the largest difference was between maternal grandmothers on the one hand and maternal grandfathers and paternal grandfathers on the other; paternal grandmothers were slightly lower. However, it must be emphasized that such a pattern could be predicted on the basis of the greater time maternal grandmothers usually spend with their grandchildren (Smith, 1981, cited by Littlefield \& Rushton, 1986), again providing a proximate explanation. In addition, it should be noted that these differences are relatively small ones. By citing only significance levels, the impression was given that the differences were large; however, the effect size $(d)$ for maternal grandmother compared with maternal grandfather was 0.2 ; for maternal grandmother compared with maternal grandfather and paternal grandmother combined, the effect size was 0.25 (the other significant effect in Littlefield \& Rushton's Table 3 was 0.15). Such differences are small ones (Cohen, 1977). 
The final hypothesis was also based on genetic relatedness and again, could have been predicted on the basis of the proximate mechanism of closeness of personal relationship with the child. However, in this case the results depend on who was estimating the grief: According to the fathers, there was no difference between maternal and paternal aunts and uncles (effect size $=0$ ), whereas according to the mother there was (effect size $=0.6$ ). The largest discrepancy arose from the mother's lower estimate of the grief shown by the paternal aunts and uncles (the effect size for the difference in the two ratings was approximately 0.4 ).

\section{General Implications}

Many of the points raised in this critique of Littlefield and Rushton (1986) have implications for any research program that seeks to apply sociobiological concepts to issues studied by social psychologists. Topics such as attachment, altruism, child abuse, and aggression have already been approached in this way.

Before embarking on such a venture, it is first necessary to ask whether the particular behavior under consideration is adaptive; that is, whether in its current circumstances, it has consequences that enhance fitness. Second, we should ask whether these same consequences would have occurred in the evolutionary environment.

Having established the functional significance of the behavior, we should then inquire through which proximate mechanisms the function operates. I would argue that it is usually only through this proximate level of analysis that ultimate functional questions can be studied in psychology. However, a common weakness in applying sociobiological principles to humans has been to argue directly from functional principles to behavior without considering proximate or mediating mechanisms. Kitcher $(1985,1987)$ has made a similar point in his detailed critique of sociobiology. As psychologists operate at the proximate level of analysis anyway, there should be no conflict between a psychological investigation of mechanisms and the careful application of functional principles to such mechanisms. The two types of explanation are not, as is often indicated, competing ones; rather, they are different types of questions about human behavior.

Essentially, what a functional approach can contribute to the investigation of human behavior is to provide a wider framework rooted in evolutionary theory, which may be useful as a guide for formulating hypotheses and for indicating what to look for when studying the proximate mechanisms (cf. Bateson, 1982a, 1984). This wider framework must, however, be based on a prior analysis of which functional rules are appropriate, and on an examination of the validity of the human-animal comparison in that particular instance (rather than on ad hoc assumptions, or a general assumption about the adaptiveness of behavior).

An example of how such general guidelines may be applied to a specific example can be seen by considering the case of human aggression from a sociobiological perspective. A widespread finding in birds and mammals (and indeed throughout the animal kingdom) is that intermale aggressiveness increases with the onset of sexual maturity or at the beginning of the breeding season, and that the proximate mechanism usually in- volves a rise in testosterone levels (Archer, 1988). This provides a good functional reason for examining possible changes in aggression in human males at around the time of puberty in relation to changing levels of testosterone and social experience (Cairns, 1986).

In conclusion, therefore, I would argue that the essential contribution of the sociobiological approach to topics in social psychology is not that it can replace studies of proximate mechanisms with alternative functional hypotheses, but that it enables some proximate mechanisms to be viewed from the wider perspectives of current utility and evolutionary origins.

\section{References}

Andersson, M., WikJund, C. G., \& Rundgren, H. (1980). Parental defence of offspring: A model and an example. Animal Behaviour, 28, 536-542.

Archer, J. (1979), Animals under stress. London: Edward Arnold.

Archer, J. (1986). Animal sociobiology and comparative psychology: A review. Current Psychological Research and Reviews, 5, 48-61.

Archer, J. (1988). The behavioural biology of aggression. Cambridge, England: Cambridge University Press.

Archer, J., \& Rhodes, V. (1987). Bereavement and reactions to job loss: A comparative review. British Journal of Social Psychology, 26, 211224.

Barash, D. P. (1979). The whisperings within. New York: Harper \& Row. Bateson, P. P. G. (1980). Optimal outbreeding and the development of sexual preferences in Japanese Quail. Zeitschrift für Tierpsychologie, 53, 231-244.

Bateson, P. P. G. (1982a). Behavioural development and evolutionary processes. In King's College Sociobiology Group (Eds.), Current problems in sociobiology (pp. 133-151). Cambridge, England: Cambridge University Press.

Bateson, P. P. G. (1982b). Preferences for cousins in Japanese Quail. Nature (London), 295, 236-237.

Bateson, P. P. G. (1984). Genes, environment and learning. In P. Marler \& H. S. Terrace (Eds.), The biology of learning (pp. 75-88). Berlin: Springer-Verlag.

Bateson, P. P. G. (1985). Review of "Not in our genes: Biology, ideology and human nature" by Rose, Kamin \& Lewontin. New Scientist, 106. 58-59.

Bowlby, J. (1960). Separation anxiety. International Journal of Psychoanalysis, 41, 89-113.

Bowlby, J. (1961). Processes of mourning. International Journal of Psychoanalysis, 42, 317-340.

Bowlby, J. (1969). Attachment and loss: Vol. 1. Attachment. London: Hogarth.

Bowlby, J. (1973). Attachment and loss: Vol. 2. Separation: Anxiety and anger. London: Hogarth.

Bowlby, J. (1980). Attachment and loss: Vol. 3. Loss: Sadness and Depression. London: Hogarth.

Cairns, R. B. (1986). An evolutionary and developmental perspective on aggressive patterns. In C. Zahn-Waxler, E. M. Cummings, \& R. Iannitti (Eds.), Altruism and aggression: Biological and social origins (pp. 58-87). New York: Cambridge University Press.

Carlisle, T. R. (1982). Brood success in variable environments: Implications for parental care allocation. Animal Behaviour, 30, 824-836.

Carlisle, T. R. (1985). Parental response to brood size in a cichlid fish. Animal Behavior, 33, 234-238.

Carpenter, F. L., \& Macmillan, R. E. (1976). Threshold model of feeding territoriality and test with a Hawaiian honeycreeper. Science, 194 , 639-642.

Cohen, J. (1977). Statistical power analysis for the behavioral sciences. New York: Academic Press. 
Coleman, R. M., Gross, M. R., \& Sargent, R. C. (1986). Parental investment decision rules: A test in bluegill sunfish. Behavioral Ecology and Sociobiology, 18, 59-66.

Crook, J. H. (1980). The evolution of human consciousness. Oxford: Oxford University Press.

Daly, M., Wilson, M., \& Weghorst, S. J. (1982). Male sexual jealousy. Ethology and Sociobiology, 3, 11-27.

Davies, N. B., \& Lundberg, A. (1984). Food distribution and a variable mating system for the dunnock, Prunella modularis. Journal of Animal Ecology, 53, 895-913.

Dawkins, R. (1976). The selfish gene. Oxford: Oxford University Press.

Dawkins, R., \& Carlisle, T. R. (1976). Parental investment, mate desertion and a fallacy. Nature, 262, 131-133.

Fisher, R. A. (1930). The genetical theory of natural selection. Oxford: Clarendon Press.

Fricke, H. W. (1980). Control of different mating systems in a coral reef fish by one environmental factor. Animal Behaviour, 28, 561-569.

Gill, F. B., \& Wolf, L. L. (1975). Economics of feeding territoriality in the goldenwinged sunbird. Ecology, 56, 333-345.

Glass, G. V., McGaw, B., \& Smith, M. L. (1981). Meta-analysis in social research. Beverly Hills, CA: Sage.

Gould, S. J., \& Lewontin, R. C. (1979). The spandrels of San Marco and the Panglosian paradigm: A critique of the adaptationist programme. Proceedings of the Royal Society of London B, 205, 581-598.

Gould, S. J., \& Vrba, E. S. (1982). Exaptation: A missing term in the science of form. Paleobiology, 8, 4-15.

Grafen, A. (1982). How not to measure inclusive fitness. Nature, 298, $425-426$.

Halpin, Z. T., \& Hoffman, M. D. (1987). Sibling recognition in the white-footed mouse, Peromyscus leucopus: Association or phenotype matching? Animal Behaviour, 35, 563-570.

Hamilton, W. D. (1964). The genetical evolution of social behavior, I and II. Journal of Theoretical Biology, 7, 1-52.

Hedges, L. V., \& Becker, B. J. (1986). Statistical methods in the metaanalysis of research on gender differences. In J. S. Hyde \& M. C. Linn (Eds.), The psychology of gender: Advances through meta-analysis (pp. 14-50). Baltimore, MD: Johns Hopkins University Press.

Hrdy, S. B. (1981). The woman that never evolved. Cambridge: Harvard University Press.

Hyde, J. S. (1981). How large are cognitive gender differences? A metaanalysis using $w^{2}$ and $d$. American Psychologist, 36, 892-901.

Kitcher, P. (1985). Vaulting ambition: Sociobiology and the quest for human nature. Cambridge, MA: MIT Press.

Kitcher, P. (1987). Precis of Vaulting ambition: Sociobiology and the quest for human nature. The Behavioral and Brain Sciences, 10, 61100.

Krebs, J. R., \& Davies, N. B. (1986). An introduction to behavioural ecology (2nd ed.). Oxford: Blackwell.

Lazarus, J. (1987). The concepts of sociobiology. In H. Beloff \& A. Colman (Eds.), Psychology survey No. 6 (pp. 192-217). Leicester, UK: British Psychological Society.

Lazarus, J., \& Inglis, I. R. (1986). Shared and unshared parental investment, parent-offspring conflict and brood size. Animal Behaviour, 34, 1791-1804.

Lewontin, R. C. (1977). Caricature of Darwin (review of R. Dawkins' "The Selfish Gene"). Nature, 266, 283-284.

Lewontin, R. C. (1978). Adaptation. Scientific American, 239, 156269.

Lewontin, R. C. (1979). Fitness, survival and optimality. In D. J. Horn, G. R. Stairs, \& R. D. Mitchell (Eds.), Analysis of ecological systems. Columbus: Ohio State University.

Littlefield, C. H., \& Rushton, J. P. (1986). When a child dies: The sociobiology of bereavement. Journal of Personality and Social Psychology, $51,797-802$.
Lund, D. A., Caserta, M. S., \& Dimond, M. F. (1986). Gender differences through two years of bereavement among the elderly. The Gerontologist, 26, 314-320.

Martin, P., \& Bateson, P. (1986). Measuring behavior: An introductory guide. New York: Cambridge University Press.

Mathes, E. W., Adams, H. E., \& Davies, R. M. (1985). Jealousy: Loss of relationship rewards, loss of self-esteem, depression, anxiety, and anger. Journal of Personality and Social Psychology, 48, 1552-1561.

Maynard Smith, J. (1977). Parental investment: A prospective analysis. Animal Behaviour, 25, 1-9.

Oakes, M. (1986). Statistical inference: A commentary for the social and behavioural sciences. Chichester, UK: Wiley.

Parkes, C. M. (1970). The first year of bereavement: A longitudinal study of the reaction of London widows to the death of their husbands. Psychiatry, 33, 444-467.

Parkes, C. M. (1972). Bereavement: Studies of grief in adult life. London: Tavistock.

Parkes, C. M. (1985). Bereavement. British Journal of Psychiatry. 146, 11-17.

Parkes, C. M. (1986). Bereavement: Studies of grief in adult life (2nd ed.). London: Tavistock.

Parkes, C. M., \& Weiss, R. S. (1983). Recovery from bereavement. New York: Basic Books.

Pollock, G. H. (1961). Mourning and adaptation. International Journal of Psychoanalysis, 42, 341-361.

Robertson, R. J., \& Biermann, G. C. (1979). Parental investment strategies determined by expected benefits. Zeitschrift für Tierpsychologie, 50, 124-128.

Rosenblatt, P. C. (1983). Bitter bitter tears: Nineteenth century diarists and twentieth century grief theories. Minneapolis: Minnesota Press.

Rosenblatt, P. C., Walsh, R. P., \& Jackson, D. A. (1976). Grief and mourning in cross-cultural perspective. New Haven, CT: Human Relations Area File Press.

Rosenthal, R. (1984). Meta-analytic procedures for social research. Beverly Hills, CA: Sage.

Sackett, G. P., \& Frederickson, W. T. (1987). Social preferences by pigtailed macaques: Familiarity versus degree and type of kinship. Animal Behaviour, 35, 603-606.

Schuchter, S. R. (1986). Dimensions of grief: Adjusting to the death of a spouse. San Francisco: Jossey-Bass.

Short, R. V. (1980). The origins of sexuality. In C. R. Austin \& R. V. Short (Eds.), Reproduction in mammals: Human sexuality (Vol. 8, pp. 1-33). New York: Cambridge University Press.

Smith, P. K. (1983). Human sociobiolagy. In J. Nicholson \& B. Foss (Eds.), Psychology Survey No. 4 (pp. 224-246). Leicester, UK: British Psychological Society.

Tallamy, D. W. (1984). Insect parental care. Bioscience, 34, 20-24.

Trivers, R. L. (1972). Parental investment and sexual selection. In B. Campbell (Ed.), Sexual selection and the ascent of man (pp. 136179). Chicago: Aldine.

Weiss, R. S. (1982). Attachment in adult life. In C. M. Parkes \& J. Stevenson-Hinde (Eds.), The place of attachment in human behavior (pp. 171-184). New York: Tavistock.

Wells, K. D. (1981). Parental behavior of male and female frogs. In R. D. Alexander \& D. W. Tinkle (Eds.), Natural selection and social behavior: Recent research and new evidence (pp. 184-197). New York: Chiron Press.

Williams, G. C. (1966). Adaptation and natural selection. Princeton, NJ: Princeton University Press.

Received August 25, 1987

Revision received December 10,1987

Accepted December 15, 1987 